\title{
Das Innovative hybrider Literatur am Beispiel Robert Walser
}

\begin{abstract}
This paper is meant to give a short introduction to the topic of the workshop „Hybridization as a Mode of Innovation“. A brief look at the notion of hybridity, which takes a prominent position in postcolonial discourse, will clarify the understanding of hybridization as it was used in our discussion. The main part is dedicated to the works of Swiss author Robert Walser. By seeking alternatives to realistic narrative, he made the combination of literary genres, association and arabesque description a key technique of his writing. Quite aware of the literary and cultural authorities of his time, his way of hybridization aimed at a playful dissolution of rigid genre limits. It also shows a tendency to subtly undermine the power structures in the society and cultural world of imperial Germany on the threshold of the twentieth century. Finally, his huge œuvre of short prose pieces shows a sense of 'translation' of language in layers, which are veiled in the everyday speech of common-sense causality.
\end{abstract}

Keywords: Hybridität; Gattungsnorm, -mischung, -hierarchie; Macht- und Autoritätsstrukturen; Diskursivität; Sprachexperiment

\section{Einleitung}

Den Anstoß für das Thema „Hybridisierung literarischer Sprachen und Ausdrucksformen als Innovationsmodus“ gab die Beschäftigung mit Robert Walser. Sein Werk zeichnet sich in hohem Maße durch einen hybriden Charakter aus und konfrontiert unweigerlich mit der Frage nach hoher und niederer Literatur, sei es rezeptionsästhetisch mit Blick auf die Literaturkritik, sei es poetologisch durch Walsers Verwendung sowohl trivialer wie hochliterarischer Stoffe sowie seine freie Kombination verschiedener Gattungen. Zentrale Aspekte seines Werkes sollen einige Grundzüge der ,Hybridisierung als Innovationmodus‘ beleuchten. 


\section{Hybrides Schreiben}

„Hybridisierung“ ist in der engeren Literaturwissenschaft kein sehr verbreiteter Begriff, während der Terminus „Hybridität“ im postkolonialen Diskurs ab den 1980er Jahren in Gebrauch ist und etwa bei dem Kulturtheoretiker Homi K. Bhabha vor allem in seiner Arbeit Die Verortung der Kultur (2000) eine zentrale Rolle spielt (vgl. Fludernik und Nandi 2001). Hier wird nicht mit dem postkolonialen Begriff gearbeitet, wobei jedoch ein kurzer Blick auf die Vorstellung des Hybriden lohnt. Im heutigen weitläufigen Sinn bezeichnen Hybride in biologischer Hinsicht die Erbgutmischung verschiedener Arten. Bei Menschen wurde von Mischling, Bastard oder Mestize gesprochen, es wurden also meist negativ konnotierte Bezeichnungen eingesetzt, die einen Kontrast zum Ideal rassischer Reinheit signalisierten. ${ }^{1}$ Im griechischen Mythos hingegen bedeuten Hybride Mischungen von göttlichen und menschlichen Wesen, wobei „Hybris“ sowohl auf Vermischtes als auch auf Anmaßung deutet (vgl. Kien 2006). Die negative Wertung des Hybriden fand in der westlichen Kulturwelt vor allem im 19. Jahrhundert im Zeitalter des Imperialismus ihren Höhepunkt, als sich die spätkolonialistische Konkurrenz zuspitzte und zugleich eine wissenschaftlich untermauerte Rassenideologie entwickelt wurde. Hier wurzelt die scharfe Abgrenzung von Nationen, Ethnien und Kulturen, die durch die Ideologisierung kultureller Differenzen ein wesentlicher Auslöser für militärische Konflikte wurde, deren Höhepunkte die beiden Weltkriege bilden.

Auch im Bereich von Kunst und Literatur wurde Vermischtes stets abwertend als Minderwertiges und Defizitäres betrachtet. Die Ideologie der „reinblütigen/ reinrassigen“ Art schwingt im Hintergrund bei der Ausdifferenzierung literarischer Gattungen mit. Das aristotelische Gattungsschema von Epik, Dramatik und Lyrik, die „drei echten Naturformen der Poesie“, wie sie Goethe (1981, 187-189) in den Noten zum West-östlichen Divan bezeichnet, bildete im 18. und 19. Jahrhundert die Folie, auf der sich der literarische Diskurs entwickelte. Auch wenn sich neue Formen, etwa die Oper, das bürgerliche Trauerspiel oder Prosaformen wie der Roman durchgesetzt haben, sie fanden sich stets einem Schema von reinen und devianten, von hohen und niederen Gattungen zugeordnet. Neue Genres und Medien künstlerischer und poetischer Darstellung wurden von Kulturkritik und im Bildungsbereich einer Gattungshierarchie unterworfen. In diese Hierarchie literarischer Genres sind auch jene kulturellen Macht- und Herrschaftsverhältnisse eingeschrieben, die über die Einzelkulturen hinaus das Weltbild

1 Wissenschaftlich gilt die Unterteilung des Menschen in Rassen als fragwürdig, neuerdings wurde im Erbgut des Homo Sapiens auch solches von Neandertalern und anderen Hominiden festgestellt (vgl. McCoy et al. 2017). 
des 19. und 20. Jahrhunderts bestimmten. Unter Hybridität versteht Bhabha eine „gegenseitige Kontaminierung“ (Fludernik 2001, 11) der kolonialen Verhältnisse, wodurch ein imaginierter „dritter Raum“ entsteht, der letztlich die Vermischung der dominanten und der dominierten Kulturen ermöglicht (Bhabha 1994, 53-56). Diese Tendenz der Hybridität wird gegenwärtig bereits als Auswuchs des postmodernen Spätkapitalismus kritisiert, der etwa in Form der Unterhaltungsindustrie die Populärkultur in ihrer enthemmten Vermischung aller Stile, Formen und Kulturen als wertlos erscheinen lässt (vgl. Kien 2006).

Wenn im Folgenden von Hybridisierung die Rede ist, so geht es vornehmlich um die Auflösung oder Transformierung herkömmlicher Gattungsformen im literarischen Schreibprozess (vgl. Hielscher 2017), die gleichwohl im Bewusstsein kultureller Hegemonie und Autorität stattfindet, wie sie Kritik und Verlagswelt oder die Institutionen von Bildung und Kunst im deutschsprachigen Kulturraum repräsentieren.

\section{Ausgangspunkt Walser}

Robert Walsers Schreiben stand von Anbeginn in einem Spannungsverhältnis zu den Regeln und Gesetzen der Gattungen. Seine Tendenz zur Vermischung von Stilen und Genres provozierte immer wieder und immer noch die Frage, ob es sich dabei um eine Schreibkrise, um ein Versagen seiner Produktivität oder um ein poetologisches Konzept handele. Die Kritik hat es sofort bemerkt, etwa Widmann (vgl. Kerr 1978, 11-38) in seiner ersten Besprechung von Walsers frühen Gedichten, oder Christian Morgenstern beim Lektorieren der Geschwister Tanner (vgl. Walser 1975, 41-45). An Walsers Texten wurden durchaus wohlwollend eine naturhafte Naivität, aber auch ein fehlender, zumindest kurzer Bildungsweg beobachtet (vgl. Stiemer 2013, 250-251). In der Tat hatte Walser auf Grund wirtschaftlicher Probleme der Eltern auf eine höhere Schulbildung verzichten müssen, sich aber autodidaktisch vor allem literarisch umfassende Kenntnisse angeeignet. Walser wurde von seinem Verleger Bruno Cassirer mit Blick auf den Buchabsatz empfohlen, im Stil von Gottfried Keller zu schreiben (vgl. Seelig 1984, 31-32). Beides, Krisenhaftes und Kreatives, wird bei Walsers nonchalanter Gattungshandhabung eine Rolle spielen, wobei für mich der Schwerpunkt auf Letzterem, auf der kreativen Poetik liegt. Ob in der Gewissheit, sich um den literarischen Erfolg zu bringen, sei dahingestellt: Walser beharrte jedenfalls auf seinem Kurs quer zu allen Gattungen, auf der Suche, wie er es formulierte, nach einer „unbekannte(n) Lebendigkeit in der Sprache“ (Walser 1986, Bd. 20, 430). Den folgenden Überblick über wesentliche Elemente von Walsers hybrider Schreibweise gliedere ich in drei 
Abschnitte: Die Auflösung und das Spiel mit Gattungsformen, das Unterlaufen von Macht- und Autoritätsstrukturen, und schließlich Übersetzung in einem ausgeweiteten Sinne. ${ }^{2}$

\section{Dekonstruktion von Gattungsformen}

Walsers Geschwister Tanner (1907) wird, wie auch Der Gehülfe (1908), noch als realistischer Roman bezeichnet. ${ }^{3}$ Aber bereits hier folgt die narrative Logik an vielen Punkten nicht mehr der realistischen Darstellungsweise, sondern es zeigt sich ein Verzicht auf Realitätsfiktion (vgl. Mohr 1994, 17). Mittels verschiedener Binnentexte wird die Entwicklung eines Erzählstranges aufgebrochen. Neben den Briefen und Traumbeschreibungen, die nicht wenig Raum einnehmen, verdeutlichen dies vor allem zwei Texte. Zum einen ist das der Aufsatz „Landleben“ (Walser 1986, Bd. 9, 146-153) des Protagonisten Simon, womit dieser während seines Aufenthalts bei seiner Schwester Hedwig Geld verdienen will. Zwar wird noch erwähnt, dass Simon den Brief zur Post bringt (Walser 1986, Bd. 9, 154), von einem Adressaten oder einer Antwort ist im weiteren Verlauf aber keine Rede mehr. Das zweite Beispiel betrifft die Aufzeichnungen seiner Jugend: „Er dachte zurück an seine Kindheit [...] und schrieb“ (Walser 1986, Bd. 9, 115). „Simon hörte auf zu schreiben. Er ging zu einer Photographie seiner Mutter, die an der schmutzigen Wand seines Zimmers hing, und preßte, indem er sich auf die Fußspitzen erhob, einen Kuß darauf. Dann zerriß er das Geschriebene [...], weil es keinen Wert mehr für ihn besaß“ (Walser 1986, Bd. 9, 124). Das Schreiben wird hier zu einer Art acte gratuit des Helden, der sich, eingeleitet von der elegischen Geste des Kusses auf das Foto seiner Mutter, gegen das eigene Schreiben richtet. Sowohl die sich nicht erfüllende Hoffnung auf Verdienst im ersten Beispiel, als auch die Wertlosigkeit und Vernichtung der Erinnerungen unterlaufen die erzählerische Entwicklung des Romangeschehens. Diese Texte, die der Leser eben gelesen hat, verselbständigen sich, indem sie verschwinden, genauer, indem ihr Verschwinden fingiert, die Autorschaft gewissermaßen annulliert wird. Zwar erweist sich die Realität des gedruckten Textes resistenter als die des Erzählgeschehens, aber

\footnotetext{
2 Schreiben als Übersetzung wird etwa in dem späten Prosastück „Diese zarten Bebänderten in gemalten Gewändern“ (Aus dem Bleistiftgebiet, Bd. 2, $475 \mathrm{ff)} \mathrm{angesprochen,} \mathrm{wo} \mathrm{sich} \mathrm{der} \mathrm{Ich-}$ Erzähler eine Übersetzung vornimmt, womit, laut Bürgi-Michaud (1996, 31), auf die Arbeit am Räuber-Roman verwiesen wird.

3 Walser selbst bezeichnet Carl Seelig $(1984,59)$ gegenüber den Gehülfen als „ganz und gar realistische(n) Roman.“
} 
damit wird bereits ein Gegenpol zur Vorstellung eines souveränen Romanautors geschaffen.

Auch das Ende des Romans, an dem der materiell wie sozial auf den Nullpunkt gesunkene Protagonist und eine geheimnisvolle Dame in den Schneewald hinausgehen (vgl. Walser 1986, Bd. 9, 332), ist denkbar weit von realistischer Erzähltradition entfernt; es zeigt vielmehr eine Wendung in eine Art Märchen. Es greift zwar das vorausgehende Märchen vom Bettelkind (vgl. Walser 1986, Bd. 9, 306-308) auf, aber anders als ein Märchen endet der Roman mit paradoxen Wendungen:

Sie müssen in ein Ohr hineinflüstern und Zärtlichkeiten erwidern lernen. Sie werden sonst zu zart. Ich will Sie lehren; [...] Wissen Sie, daß ich Ihre arme, glückliche Gefangene bin? [...] Ich muß Ihnen so viel sagen [...]. Kein Wort mehr, kein Wort mehr. Kommen Sie nur. - (Walser 1986, Bd. 9, 332)

Simon soll zärtlich sein, um nicht zu zart zu werden, die Frau nennt sich seine Lehrerin und zugleich seine „glückliche Gefangene“, sie will viel sagen und fordert Schweigen. Diese paradoxe Unbestimmtheit wird noch verstärkt und vollends ins Nichtsprachliche getrieben durch einen an das Ende gesetzten Gedankenstrich.

Aber Walsers Schreiben kennt nicht nur die Richtung weg von Realitätsabbildung. In seinen frühen Dramoletts und den späteren Nacherzählungen von Märchen ${ }^{4}$ ist der umgekehrte Impuls zu beobachten: Realität und Gegenwart, Metareflexion und Rationalität dringen in das Märchen ein. Hat man bei den Grimms je ein so scharfzüngiges Schneewittchen wie in Walsers gleichnamiger Bearbeitung von 1901 gesehen, wenn es dem plaudernden Prinzen über den Mund fährt? „Ihr sprecht ja wie ein Wasserfall/ vom Schweigen, und schweigt doch nicht“ (Walser 1986, Bd. 14, 82). Walsers frühe Märchenfiguren beginnen zu argumentieren, sie reflektieren selbstreferentiell ihre Rolle im Märchen, ja die Gattung selbst. Das Märchen, so Schneewittchens Stiefmutter, verleumde sie: „Ach, glaub’ doch/ solch aberwitzgem Märchen nicht,/ das in der Welt begierig Ohr/ die Nachricht schüttet, ich sei toll/ aus Eifersucht, bös von Natur,/ was alles ein Geschwätz nur ist“ (Walser 1986, Bd. 14, 78).

Der Jäger hingegen führt das Märchen als Beweis seiner Unschuld an, womit Walser mit der Doppelbedeutung - Geschichte/Lüge - dieses Wortes spielt. Der Prinz bedauert wiederum, Schneewittchen aufgeweckt zu haben:

4 Vgl. Anna Fattoris (2011, 177-198) eingehende Untersuchung von Walsers häufigen Umbildungen bekannter Volksmärchen, sein Experimentieren mit Märchenfiguren und -motiven, seine Glossen und metasprachlichen Bemerkungen zu Märchen. 
Verzeih der Lieb’, daß sie dich aus dem Sarge nahm, dem gläsernen, worin du lagst/ mit Rosenwangen, offnem Mund/ und Atem, der Lebend'gen gleich./ Dies war ein Bild zum Sterben süß:/ Hätt' ich es doch gelassen so,/ dann kniete Liebe noch vor dir. /

Schneewittchen: Schau, schau? Nun ich lebendig bin,/ wirfst du mich wie die Tote weg!/ Wie seltsam seid ihr Männer doch. (Walser 1986, Bd. 14, 86)

In Aschenbrödel (1901) bemerkt die Protagonistin, dass der Prinz recht unzeitgemäß mit Schwert und Spieß daherkomme (vgl. Fattori 2011, 182):

Ihr seid ein Prinz,/ ein Königssohn, das sieht man Euch/ an dem verschollnen Wesen an,/ das unsrer Zeit sich nicht mehr schmiegt./ Ein Mantel ist von Hermelin/ Euch um die Schulter angehängt./ Ihr tragt ein Schwert und einen Spieß,/ wie das wohl nimmer Brauch mehr ist; (Walser 1986, Bd. 14, 41)

Walsers Beschreibungsimpuls zeigt folgende Gegenläufigkeiten: Wirklichkeitsdarstellung wird durch Fiktives, Fiktiv-Märchenhaftes hingegen durch Gegenwartsoder Realitätsfingierung angereichert. Neben der Erzähl- und Bedeutungsebene lässt sich bereits in den frühen Werken eine Tendenz zur Selbstreferentialität seines Schreibens ausmachen, die sich später verstärken wird. Sein Roman bleibt nicht in den Grenzen der meist mit dem realistischen Erzählen gleichgesetzten, überlieferten Form, während den Märchenfiguren Reflektiertheit und psychologische Charakterzüge angedichtet werden. Diese Auflösung eng gefasster Gattungsformen ließe sich ebenso mit Walsers ironischer Verwendung von Gattungsnamen wie Novelle, Märchen, Geschichten, Brief, Vorspiel, Portraitskizze usw. in den Titeln seiner Kurzprosa illustrieren. Genette (1993, 13-14) bezeichnet Texte, die sich explizit einer literarischen Gattung zuordnen, als Architexte, die er als Spezialform der Intertextualität deutet. Er behauptet, dass Texte nicht von sich aus die Gattung bestimmen, sondern Leser und Kritiker, stellt aber zugleich fest: „Das Wissen um die Gattungszugehörigkeit eines Textes lenkt und bestimmt, wie man weiß, in hohem Maß den ,Erwartungshorizont` des Lesers und damit die Rezeption des Werkes“ (Genette 1993, 14). Walsers ironische Provokation, die Entscheidung über die Gattung bereits durch den Titel an sich zu reißen, ist zugleich Aufforderung an den Leser, die Gültigkeit seiner Gattungsbezeichnung zu überprüfen und sich generell Gedanken über Gattungen zu machen.

In der Forschung wird von Walsers „Verweigerung der Normerfüllung der Gattungen“ gesprochen, von seinem Aufbegehren gegen den Gattungszwang (Lamping 2011, 22), die dem Leser „Gattungstoleranz“ abverlange (Utz 2011, 37). Hier würde Walser protestieren und dagegen halten, dass nicht jeder Leser stets auf die Erfüllung der Gattungsnormen nach germanistischen Maßstäben poche und nur goutieren könne, was den Regeln der reinen Gattung entspräche. In der Tat ist der Leser bei Walsers Texten immer aufgefordert, ständig die Ebenen zu 
wechseln, ja auf mehreren Ebenen gleichzeitig zu lesen, auf einer romantischen, auf einer modernen lebensweltlichen, auf einer historischen, auf einer Nonsenseund auf einer kreativ-sprachspielerischen Ebene, auf einer lautmalenden und einer reimenden. Was Peter Utz „ambivalente Lesbarkeit“ (Utz 2011, 35) nennt, deutet Fuchs (1993, 131-132) noch positiver als dialogisches Element, mit dem der Leser als Kommunikations- und Spielpartner in eine Lach- und Reflexionsgemeinschaft einbezogen wird.

\section{Auflösung von Macht- und Autoritätsstrukturen}

Mit der hybriden Auflösung der Gattungsformen und der Diskursivität des Erzählens geht eine Auflösung von Macht- und Autoritätsstrukturen einher. Betrachten wir wieder Geschwister Tanner, dann erleben wir gleich zu Beginn eine Machtumkehrung zwischen dem stellensuchenden Protagonisten und dem Buchhändler:

,Ich will Buchhändler werden', sagte der jugendliche Anfänger, ,ich habe Sehnsucht darnach und ich weiß nicht, was mich davon abhalten könnte, mein Vorhaben ins Werk zu setzen. [...] Sehen Sie, mein Herr, ich komme mir, so wie ich jetzt vor Ihnen dastehe, außerordentlich dazu geeignet vor, Bücher aus Ihrem Laden zu verkaufen, so viele, als Sie nur wünschen können zu verkaufen [...]. (Walser 1986, Bd. 9, 7)

Dabei wird dieser Umschlag vor allem durch einen eloquenten Wortschwall des Helden erzeugt, dem sich der Prinzipal unvermutet ausgesetzt sieht. Das Rollenverhältnis von Stellensucher und Arbeitgeber kippt vollends, wenn Simon dem Händler den Wert von Zeugnissen ausredet und ihm Mut zur eigenen Entscheidung macht:

Nein, Herr, Erkundigungen taugen in der Regel keinen Pfifferling, ich rate Ihnen, wenn ich mir Ihnen, dem alten Herrn gegenüber, einen Ratschlag herausnehmen darf, entschieden davon ab, [...] wenn Sie gedenken, mich zu verwenden, so bitte ich Sie, etwas mehr Mut zu bezeigen als die meisten andern Prinzipale. (Walser 1986, Bd. 9, 9)

Natürlich handelt es sich bei dieser Überlegenheit nur um eine flüchtige, rhetorisch hervorgezauberte Umkehrung der realen Kräfteverhältnisse, die letztlich nicht angestrebt ist. Seine eigentliche Berufung sieht Simon im Dienen, worin ein Grundmotiv von Walsers Literatur liegt. ${ }^{5}$

5 Ich gehe hier bewusst nicht auf Jakob von Gunten ein, worin das Diener-Motiv zu einer komplexen zeitkritischen Metaphorik gesteigert wird, da wir dazu einen eigenen Beitrag haben. 
Im Räuber-Roman (1925/1972) wird das instabile, dynamische Machtverhältnis von Herr- und Dienerschaft, das bereits in der ambivalenten Aufspaltung von Ich-Erzähler und Räuber-Figur angelegt ist, offen ausgesprochen: Die aktiv angenommene Untergebenenrolle des Räubers verkehrt sich ins Gegenteil, sollte sich jemand die Herrenrolle anmaßen (vgl. Walser 1986, Bd. 12, 144). Dieser instabile Zustand gilt gleichermaßen für das Herrschen:

Und auf diese Weise wäre jede Herrschaft schwankend. Und die Dienenden, die, die von Schlägen getroffen werden, wären die Stärkeren, die von sich Erfüllteren. Und die Herrschenden wären die Beunruhigten, die Hülfsbedürftigen. [...] Und das Herrschen wäre eine Aufgabe, die über die Kraft ginge und sie darum krank mache. (Walser 1986, Bd. 12, 73-74)

Diese Reflexionen nehmen ihren Ausgang bei der Szene eines Handgemenges auf der Straße zwischen dem Räuber und einem Mann, der dem Räuber einen Stockschlag auf die Hand verpasst und mit einem Revolver bedroht, weil dieser seiner Frau keinen Platz gemacht hatte (vgl. Walser 1986, Bd. 12, 71-74). In dieser Passage, die eine Reihe assoziativer Reflexionen auslöst, zeigt sich der gleitende Übergang von einer zur nächsten Bedeutungsebene, der hier nur in Stichwörtern angedeutet werden kann. Unter anderem lassen sich folgende Ebenen erkennen: eine soziale im Konflikt zwischen Räuber und Herr; eine subjektive: Der Räuber sieht die geschlagene Hand als Opfer seines hochmütigen Kopfes; eine historische: Der unterlegene Räuber geht stolz von dannen, als sei es das Schlachtfeld Marignano von 1515, auf dem die Eidgenossen im Konflikt mit Frankreich einen geordneten Rückzug vornahmen; und eine Märchenpersiflage: Der des Lachens unfähigen Königstochter wird vom dummen Handwerksburschen das ersehnte Lachen entlockt, der dafür wie versprochen, wenn auch widerwillig, ihre Hand erhält. Spielerisch und assoziativ werden auf diese Weise paradoxe, poetische und komische Gedankenbewegungen initiiert.

Im Räuber-Roman wird ein dissoziierter Erzählverlauf entwickelt, wie er seit Laurence Sternes Tristram Shandy (1759-1767) zum Repertoire modernen Erzählens gehört. Nahezu alle Andeutungen und Motive, die im Räuber vom Erzähler zunächst fallen gelassen oder aufgeschoben werden, kommen wieder zum Vorschein, worin das narrative Raffinement der bewusst gestalteten Diskontinuität liegt. Der Text verweigert einen diskursiven Erzählverlauf, von dem erwartet wird, einfach und verständlich, dazu belehrend und unterhaltsam zu sein. Der Erzähler spricht denn auch von einem „besonnene(n) Buch [...], aus dem absolut nichts gelernt werden kann“ und das folglich keinerlei „Anhaltspunkte fürs Leben“ (Walser 1986, Bd. 12, 12) biete. Trotz der verwirrenden Fülle an Episoden und Andeutungen behauptet er, stets den Überblick über seine Geschichte zu bewahren. Diese Verweigerung der überschaubaren Geschichte ist auf poetologischer 
Ebene seine Form, sich den Zwängen der literarischen Hierarchie zu entziehen. Hier spalten sich indes die Meinungen der Kritiker: Während zum einen von „der drohenden Einsicht in die Unfähigkeit zur epischen Formerfüllung“ (Osterkamp 1991, 233) gesprochen wird, argumentiert W.G. Sebald:

In der Tat zeugt die Unverkrampftheit, mit der er die beträchtlichen strukturellen Schwierigkeiten und das Changieren der Stimmungen zwischen tiefer Verstörung und eine nur mit dem Wort Allegria richtig bezeichneten Leichtigkeit meistert, von einem hohen Maß an künstlerischer und moralischer Souveränität. (Sebald 1998, 157 f)

Walsers Erzählweise ist dabei konsequent anti-ideologisch, insofern sie die Räuber- oder Erzähler-Gedanken ebenso aufhebt und ironisiert wie den kritisierten Ausgangspunkt der Macht- und Überlegenheitspositionen. Es geht aber nie um eine bloße Umkehr der Machtverhältnisse. In einer neuen Form des Bezugs treten Stärke und Schwäche, Macht und Ohnmacht in eine dynamische Wechselbeziehung.

Lamping macht in Walsers Kurzprosa vor allem der Bieler Zeit (1913-1920) eine Verschiebung und Flucht in die Fiktion aus und sieht gerade ,in ihrer Hybridität zugleich ein Symptom der Krise“. In vielen Texten entdeckt er eine „ermüdende Aufzählung und Reihung von Wörtern, die oft nur tautologisch ist“ und einen „poetische(n) Redezwang“ verrate (Lamping 2011, 24). Im scheinbar sinnlos-tautologischen Evozieren von Naturschönheiten lässt sich durchaus ein Anschreiben gegen eine Krise feststellen, nämlich die Krise des Ersten Weltkriegs, der Europa im Chaos versinken lässt. Walser stellt dem offen formulierten Pazifismus Hesses seine eigene Art von Friedensbotschaft an die Seite, nämlich den Krieg durch die Idyllik seiner Naturstücke schlichtweg aus der Welt zu verbannen. Das 1917 erstmals veröffentlichte Prosastück „Schneien“ mag dafür ein Beispiel sein. Unablässig werden die Gegenstände und Lebewesen aufgereiht, auf die der Schnee herabfällt, wobei er die vielfarbige und -gestaltige Landschaft in ein weißes Einerlei friedlich vereint. Dann jedoch erfolgt am Schluss die Wendung hin zu einem im Krieg gefallenen Soldaten, der ebenfalls unter der Schneedecke verschwindet. Seine Frau, der dessen Schicksal plötzlich vor Augen erscheint, sitzt weinend am Tisch (vgl. Walser 1986, Bd. 5, 159-162). Stiemer (2013, 156-183) analysiert Walsers Bieler Idyllen im Kontext ihrer Publikationsform, insbesondere in der Neuen Züricher Zeitung. Zahlreiche Prosastücke erschienen durch einen schwarzen Strich abgesetzt im unteren Teil der Titelseite, während der Teil über dem Strich den Kriegsberichten von den verschiedenen Fronten gewidmet war. Um die Neutralität der Schweiz zu bewahren, wurden die Meldungen aller Kriegsparteien unkommentiert abgedruckt. Erst aus dieser Kombination lässt sich das Potential an Irritation und stummem Protest von Walsers idyllenhaften Beiträgen erschließen. Auch Texte wie „Der Soldat“ (vgl. Walser 1986, Bd. 16, 333- 
334) oder „Beim Militär“ (vgl. Walser 1986, Bd. 16, 337-339), die sich scheinbar aktuellen Zeitthemen widmen, demaskieren zum einen stilistisch durch Wiederholungen und leere Worthülsen ironisch die Hohlheit militaristischer Ideologie. Zum anderen strafen sie im Kontrast zu den Frontberichten im oberen Seitenteil die angestimmte Kriegs- und Soldatenromantik seiner Prosatexte Lügen, worin gerade ihr kritisches Kalkül liegt.

\section{Walsers Übersetzung von Welt in Sprache}

Hybridisierung ist für Walser ein Verfahren, den Stillstand sedimentierter und fixierter Diskurse zu verflüssigen, diese neu aufzumischen. Authentische, biographische, fiktionale, intertextuelle Elemente konstituieren in ihrer Mischung und Kombination verschiedener Gattungen und Darstellungsebenen neue sprachliche Ausdrucksformen. Für Walser ist Sprache gewissermaßen eine open source, über die er im Sinne von Wissen, Information und Kreativität, Humor und Komik frei verfügt. Sprache ist das Medium, in dem er die durch die materielle, soziale und politische Wirklichkeit fixierten Strukturen auflöst, sie ihrer Autorität beraubt, umformt, und dieser Umformung die Gestalt seiner Texte gibt. Sein Erzählduktus zersetzt mit der Wort- und Syntaxebene die Bedeutungsebene. Er löst Wort- und Gedankengebilde ins Klangliche auf, schafft Vieldeutigkeiten, Assoziationen, Anspielungen, kurz: Er treibt die polyphone Vielschichtigkeit der Sprache hervor. Ein kurzer Blick auf die erwähnte Straßen-Szene mag zur Illustration dienen:

\footnotetext{
Er hatte der Dame nicht Platz gemacht, die mit dem Herrn ging, [...] Herrgott, wie der sich für seine Gemahlin einsetzte. [...] „Dir will ich zeigen, was Höflichkeit ist.“ [...] [D]ie arme Frau [...] schrie (laut): „Um Gotteswillen, Willi!“ Der Aufschrei durchschnitt die Luft wie ein regelrechter Notschrei. [...] ich schieße“, schrie oder rief bloß der Herr Immermann oder Immerhin. In der Tat schien er immerhin ein aufrichtiger, seiner Frau ergebener Mensch. (Walser 1986, Bd. 12, 71)
}

Wort- und Lautwiederholungen, Relativierungen, stereotype Reihungsketten, Neologismen, Nominal- und Verbalbildungen werfen den Fortgang logischer, zeiträumlicher Argumentation und Beschreibung aus der diskursiven Bahn. Walser übersetzt auf diese Weise kaleidoskophafte Wahrnehmungen, Erfahrungen, Beobachtungen, Urteile und Klischees in klingendes Sprachmaterial. Ein Beispiel aus Geschwister Tanner illustriert, dass dies bereits sehr früh Element seiner Poetik ist. Es beschreibt die Hauptfigur beim Tischdecken: 
Er mußte ein sauberes, weißes Tischtuch über den Tisch breiten, daß die Falten nach oben zu liegen kamen, dann die Teller hinlegen, so, daß der Tellerrand nicht über den Tischrand hinausragte, dann Gabel, Messer und Löffel hinlegen, Gläser aufstellen und eine Karaffe mit frischem Wasser, Servietten auf die Teller legen und das Salzgefäß auf den Tisch stellen. Stellen und legen, hinlegen und anfassen und hinstellen, [...] Gläser nicht aneinanderklirren, und Teller nicht klappern lassen, aber über ein vorkommendes Klappern und Klirren auch nicht erstaunt sein [...]. (Walser 1986, Bd. 9, 199)

Wortwiederholungen und -variationen verdichten das Wortmaterial, Reim- und Klangfolgen evozieren einen sprachlichen Rhythmus, der die Tätigkeit in den Hintergrund rücken lässt.

Ein weiteres Beispiel stammt aus dem längeren Prosatext Naturstudie, erstmals 1916 in Die Rheinlande 6 erschienen:

Fröhliches Kindheitsland, lichte Elternerde, hohe Felsen, heitere, kleine Wege, Stadt- und Bauernhäuser. Gottes und der Menschen helle Welt und reizende, anmutige Verstecke, Büsche, Gräser, Pflanzen, Apfel- und Kirschbäume, tiefsinnig-blasse Lilien, üppig-schöne Rosen im dunkelgrünen heimeligen Garten, Helligkeit des frühen Morgens, die du mich götterhaft mit frischer Hoffnung anblitztest, [...]. Rötliche Wolken über abendlich-bleichem See, Morgenrot, Wind, Regen und süße Mittagshitze, wie dankbar sah ich euch an, wie tief empfand ich euch, wie glücklich war ich im traulichen, zeitvergeudenden Verkehr und im liebenden Umgang mit euch. Niemals werde ich zu bereuen haben, daß ich Aug und Ohr, alle Aufmerksamkeit, Sinne und Gedanken und die Seele eifrig euch hingab. (Walser 1986, Bd. 7, 79)

Idyllische Klischees evozieren, bis zur Kitschhaftigkeit gesteigert, eine paradieshafte Naturerfahrung, die wiederum im denkbar größten Kontrast zur in den Medien geschilderten Weltkriegsrealität ${ }^{7}$ steht und darin zugleich eine tragisch zu nennende Verlusterfahrung artikuliert.

Walsers Wortkaskaden, angefangen von den frühen Arbeiten bis zum Räuber und dem späten Werk der Mikrogramme, bilden vor allem Klänge, Assoziationen, Oppositionen, An-, Quer- und Gegenklänge, die sich dem diskursiven Geschichtenerzählen entwinden und die gerade darin die Realität in ihrer destruktiven Brutalität bewusst machen. Angesichts dieser redundanten, oft zu Prosagedichten verdichteten, in rhythmische Aufzählungen und Reihungen gesteigerten Texte

\footnotetext{
6 In digitalisierter Form in der Universitätsbibliothek Heidelberg zugänglich. http://digi.ub.uniheidelberg.de/diglit/rheinlande1916 (24. Februar 2018).

7 Stiemer, der die Publikationssituation genau recherchiert, merkt zu den Idyllen der Bieler Zeit an: „Die beschriebenen kontextuellen Kontraste zwischen Weltkrieg und Idylle müssen somit als Ergebnisse eines produktionsästhetischen Kalküls betrachtet werden, das auf eine oppositionelle Haltung des Autors schließen lässt.“ (Stiemer 2013, 172)
} 
ließe sich sagen, Walser rappt! Walsers Prosa formt so Welt in Sprache um, indem sie musikalischen Klanggebilden, synästhetischer Malerei oder einer Sprache der Bühne angenähert wird. Sie erzeugt mittels dieser sprachspielerischen Poetik der Hybridität eine eigene Wahrnehmungsform des Sprachlichen.

\section{Schluss}

Robert Walser ging seit Beginn seines Schreibens sehr frei mit dem Sprachmaterial und den literarischen Formen um. Früh bekam er dafür von der Kritik den Stempel einer naiven Naturbegabung und eines gewissen bildungsfernen Dilettantismus aufgedrückt. Geflissentlich wurde lange Zeit übersehen, dass er durchaus über ein breites literarisches Wissen verfügte, mit dem er in so subtiler wie komplexer Weise intertextuell arbeitete. Mit Leichtigkeit kombinierte er diverse Stoffe aus Märchen und Mythologien, aus trivialer und hoher Literatur, aus Fakten des Tagesgeschehens und historischen Begebenheiten zu seinen Textkollagen. Was sich in den Augen von Vertretern der Hochkultur wie mangelnder Respekt vor der Tradition oder begrenzte Gestaltungskraft ausnahm, erweist sich bei genauerem Hinsehen als sein originärer Anspruch, neue Wege literarischen Ausdrucks zu suchen.

Walsers Versuche, über das diskursive und realistische Erzählen hinaus mit dem Wort- und Satzmaterial möglichst viele Bedeutungs-, Assoziations- und Klangfacetten anzustoßen, ähneln in manchen Zügen Experimenten des Surrealismus oder auch eines James Joyce. Bedeutungen werden sprachlich nicht mehr eindeutig festgelegt, sondern sie schwingen in einem mehrstimmigen Klangbild, sie manifestieren sich darin für Momente und lösen sich ebenso schnell wieder auf. Darin liegt auch der Verzicht auf die Anmaßung intellektueller, weltanschaulicher Autorität und Macht.

Nicht die getreue Einhaltung der Gattungsregeln, sondern das konsequente Experimentieren damit hat Walsers Werk über die Zeit hinweg modern und lebendig gehalten. Es erweist sich bis in unsere Gegenwart hinein gerade in seiner Hybridität als vielfältige Inspiration für junge Autoren und Künstler und lädt unvermindert zu neuen Entdeckungen und Übersetzungen in andere Sprachen und Medien ein. Hierin entfaltet sich das innovative Potential von Walsers Literatur. Obgleich es sich hier um seinen Individualstil handelt, konnten aus seiner Poetik wesentliche Elemente für die Hybridisierung identifiziert werden: die Skepsis gegenüber fixierten Gattungsformen, das Hinterfragen von Autorität und Werten sowie das Experimentieren mit neuen Ausdrucksformen von Sprache und Wahrnehmung. 


\section{Literaturverzeichnis}

Bürgi-Michaud, Thomas. Robert Walsers „mühseligkeitenüberschüttetes Kunststück“: eine Strukturanalyse des „Räuber“-Romans. Bern: Lang, 1996.

Fattori, Anna, und Kerstin Gräfin von Schwerin (Hg.). „Ich beendige dieses Gedicht lieber in Prosa“. Robert Walser als Grenzgänger der Gattungen. Heidelberg: Winter, 2011.

Fattori, Anna. „,Dieses Ungeheuer liebte mich, [...] du aber, Befreier, liebst mich nicht.' Robert Walser und das Märchen“. „Ich beendige dieses Gedicht lieber in Prosa“. Robert Walser als Grenzgänger der Gattungen. Hg. Anna Fattori und Kerstin Gräfin von Schwerin. Heidelberg: Winter, 2011. 177-198.

Fludernik, Monika, und Mirjam Nandi. „Hybridität. Theorie und Praxis“. Polylog. Zeitschrift für interkulturelles Philosophieren 8 (2001): 7-26.

Fuchs, Annette. Dramaturgie des Narrentums. Das Komische in der Prosa Robert Walsers. München: Fink, 1993.

Genette, Gérard. Palimpseste. Die Literatur auf zweiter Stufe. Frankfurt/M.: Suhrkamp, 1993. Goethe, Johann Wolfgang von. „West-östlicher Divan“. Werke. Hamburger Ausgabe Bd. 2. Hg. Erich Trunz. München: Beck, 1981.

Hielscher, Martin. „Was ist hybride Literatur“. Sprache für die Form 11 (2017), http://www.designrhetorik.de/was-ist-hybride-literatur/ (24. Februar 2018).

Hinz, Klaus-Michael, und Thomas Horst (Hg.). Robert Walser. Frankfurt/M.: Suhrkamp, 1991.

Kerr, Katharina (Hg.). Über Robert Walser. 3 Bde. Frankfurt/M.: Suhrkamp, 1978/1979.

Kien Nghi Ha. „Die Grenze überqueren? Hybridität als spätkapitalistische Logik der kulturellen Übersetzung und der nationalen Modernisierung.“ Transversal 2006, http://eipcp.net/ transversal/1206/ha/de (24. Februar 2018).

Lamping, Dieter. „Das Rätsel der kleinen Form. Gattungsmischung in Robert Walsers Poetenleben“. „Ich beendige dieses Gedicht lieber in Prosa“. Robert Walser als Grenzgänger der Gattungen. Hg. Anna Fattori und Kerstin Gräfin von Schwerin. Heidelberg: Winter, 2011. 11-26.

McCoy, Rajiv C., Jon Wakefield und Joshua M. Akey. „Impacts of Neanderthal-Introgressed Sequences on the Landscape of Human Gene Expression“. Cell 168 (2017): 916-927, http://www.cell.com/cell/pdf/S0092-8674(17)30128-9.pdf (24. Februar 2018).

Mohr, Daniela. Das nomadische Subjekt. Ich-Entgrenzung in der Prosa Robert Walsers. Frankfurt/M. u. a.: Lang, 1994.

Osterkamp, Ernst. „Commis, Poet, Räuber. Eigengesetzlichkeit und Selbstaufgabe bei Robert Walser“. Robert Walser. Hg. Klaus-Michael Hinz und Thomas Horst. Frankfurt/M.: Suhrkamp, 1991. 217-239.

Sebald, W.G. „Le Promeneur Solitaire. Erinnerung an Robert Walser“. Logis in einem Landhaus. München: Hanser, 1998.

Seelig, Carl. Wanderungen mit Robert Walser. Zürich und Frankfurt/M.: Suhrkamp, 1984.

Stiemer, Hendrik. Über scheinbar naive und dilettantische Dichtung. Text- und Kontextstudien zu Robert Walser. Würzburg: Königshausen \& Neumann, 2013.

Walser, Robert. „Beim Militär“. Sämtliche Werke in Einzelausgaben. Bd. 16. Hg. Jochen Greven. Zürich: Suhrkamp, 1986. 337-339.

Walser, Robert. Briefe. Hg. Jörg Schäfer unter Mitarbeit von Robert Mächler. Genf: Kossodo, 1975.

Walser, Robert. „Der Räuber“. Sämtliche Werke in Einzelausgaben. Bd. 12. Hg. Jochen Greven. Zürich: Suhrkamp, 1986. 
Walser, Robert. „Der Soldat“. Sämtliche Werke in Einzelausgaben. Bd. 16. Hg. Jochen Greven. Zürich: Suhrkamp, 1986. 333-334.

Walser, Robert. „Diese zarten Bebänderten in gemalten Gewändern“. Aus dem Bleistiftgebiet. Bd. 2. Hg. Bernhard Echte und Werner Morlang. Frankfurt/M.: Suhrkamp, 1985. 475-478.

Walser, Robert. „Geschwister Tanner“. Sämtliche Werke in Einzelausgaben. Bd. 9. Hg. Jochen Greven. Zürich: Suhrkamp, 1986.

Walser, Robert. „Meine Bemühungen“. In: Sämtliche Werke in Einzelausgaben. Bd. 20. Hg. Jochen Greven. Zürich: Suhrkamp, 1986, 427-430.

Walser, Robert. „Naturstudie“. In: Sämtliche Werke in Einzelausgaben. Bd. 7. Hg. Jochen Greven. Zürich: Suhrkamp, 1986. 60-82.

Walser, Robert. „Schneewittchen“. In: Sämtliche Werke in Einzelausgaben. Bd. 14. Hg. Jochen Greven. Zürich: Suhrkamp, 1986. 74-115.

Walser, Robert. „Schneien“. In: Sämtliche Werke in Einzelausgaben. Bd. 5. Hg. Jochen Greven. Zürich: Suhrkamp, 1986. 159-162.

Utz, Peter. „Erschriebenes Leben. Ist Robert Walsers Poetenleben eine ,Autofiktion“?“ „Ich beendige dieses Gedicht lieber in Prosa". Robert Walser als Grenzgänger der Gattungen. Hg. Anna Fattori und Kerstin Gräfin von Schwerin. Heidelberg: Winter, 2011. 27-42.

Franz Hintereder-Emde, Professor für Germanistik an der Universität Yamaguchi. Studium der Germanistik, Philosophie und Japanologie an der Universtität Erlangen-Nürnberg. Forschungsschwerpunkte sind Komparatistik vor allem japanischer und deutschsprachiger Literatur der Moderne, literarische Übersetzung, Kulturthemen und interkulturelle Erziehung. 